\title{
O Museu como espaço de transversalidade
}

The museum as a place of transversality

José Luís Schifino Ferraroa

Roberta Gigliob

\section{Editor}

Maria Inês Côrte Vitoria

PUCRS, RS, Brasil

\section{Equipe Editorial}

Pricila Kohls dos Santos

PUCRS, RS, Brasil

Marcelo Oliveira da Silva

PUCRS, RS, Brasil

Carla Spagnolo

PUCRS, RS, Brasil

Rosa Maria Rigo

PUCRS, RS, Brasil
RESUMO: O presente trabalho visa abordar a temática da transversalidade a partir da orientação dos Parâmetros Curriculares Nacionais (PCNs) como possibilidade para uma prática pedagógica significativa em um espaço não formal de educação: os museus. Tomando como referência o Museu de Ciências e Tecnologia da Pontifícia Universidade Católica do Rio Grande do Sul (MCT-PUCRS) em sua área expositiva, o artigo pretende abordar dois temas transversais específicos, "saúde" e "meio ambiente", discutindo e propondo uma ressignificação das práticas educativas tradicionais que se inscrevem no âmbito do ensino de ciências.

Palavras-chave: Ensino de ciências. Museu. Temas trasnversais. Educação.

ABSTRACT: The present work aims to broach the issue of transversality from the guidance of National Curriculum Guidelines (PCN, portuguese acronym) as a possibility for a significant pedagogical practice in a nonformal education space: museums. Taking as a reference the Museum of Science and Technology of Pontifícia Universidade Católica do Rio Grande do Sul (MCT-PUCRS) in its exhibition area, the article aims to broach two specific cross-cutting themes, "health" and "environment", discussing and proposing a (re-)significance of traditional educational practices which fall within the sphere of science education.

Keywords: Science education. Museum. Cross-cutting themes. Education.

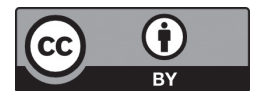

A matéria publicada neste periódico é licenciada sob forma de uma Licença Creative Commons - Atribuição 4.0 Internacional. http://creativecommons.org/licenses/by/4.0/

\footnotetext{
a Doutor em Educação. Professor da Faculdade de Biociências e do Programa de Pós-Graduação em Educação em Ciências e Matemática da Pontifícia Universidade Católica do Rio Grande do Sul (PUCRS). <jose.luis@pucrs.br>.

b Licenciada em Ciências Biológicas e Mestranda do Programa de Pós-Graduação em Educação em Ciências e Matemática da Pontifícia Universidade Católica do Rio Grande do Sul (PUCRS). E-mail: <roberta.giglio@pucrs.br>.
} 
Museu de Ciências e Tecnologia da Pontifícia Universidade Católica do Rio Grande do Sul (MCT-PUCRS) tem como principal objetivo a divulgação científica por meio de atividades que se inscrevem no âmbito educação, da extensão e da pesquisa. A popularização da ciência - que acaba por se constituir como seu principal escopo aproxima o público que frequenta o museu de experimentos construídos para facilitar a compreensão de princípios e leis científicas a partir da interação.

Os museus interativos de ciências representam um espaço educativo complementar à educação formal, possibilitando a ampliação e a melhoria do conhecimento científico de estudantes, bem como, da população em geral [...] o papel educacional dos museus de ciências é muito maior do que simplesmente "dar aulas a crianças de escola" nesse ambiente. (SOARES; SILVA, 2013, p. 177)

O resultado desta interação é positivo, pois é possível aprender ciências e identificar nos fenômenos naturais e eventos cotidianos elementos científicos que em determinadas situações poderiam passar despercebidos.

Conforme afirma Navas (2008, p. 15) é de interesse que este movimento de popularização da ciência tome corpo. Ele contribui não apenas para o aprimoramento da própria educação de um país, na medida em que aquilo que é científico passa a ser aproximado das pessoas, mas também um amplo acesso à ciência pode contribuir para o estabelecimento de um quadro de maior equidade social. Além de auxiliar no desenvolvimento de políticas e iniciativas de desenvolvimento em nível nacional.

Nas últimas décadas, a maioria dos países latino-americanos tem reconhecido a importância de popularizar a Ciência e a Tecnologia (C\&T) no processo de construção de um ambiente de equidade social e econômica. Nesse contexto, pode-se identificar uma situação comum para vários de nossos países, que é a existência de valiosas trajetórias de divulgação da ciência e da tecnologia e a necessidade de formular políticas ou planos nacionais que permitam articular as iniciativas existentes e promover o desenvolvimento de novas iniciativas. (NAVAS, 2008, p. 15)

Com relação à educação, a divulgação científica observada a partir de iniciativas de popularização da ciência tem reflexos positivos. Trabalhar tópicos relacionados ao ensino de ciências de maneira não usual, rompendo com os limites das disciplinas isoladas, em um espaço de educação não formal como o museal, mobiliza uma forma de entendimento e compreensão mais significativos. A parceria estabelecida entre museus e escolas se constitui em ganho na aprendizagem por parte dos alunos, tornando-os mais protagonistas de seu próprio processo de ensino, além de 
instigá-los a resolver problemas que aparecem - no caso específico de um museu de ciências - no funcionamento dos próprios experimentos.

Inocêncio $(2012$, p. 1) reafirma estes elementos. Ainda, coloca a importância do relacionamento e das trocas entre instituições: a escola como espaço formal dos processos de ensino e de aprendizagem com outras que podem contribuir para ambos, mas que não tem o compromisso de que os mesmos venham a ocorrer por meio do formalismo e do tradicionalismo pedagógico das salas de aulas do senso comum. Dentre estas últimas se encontram os museus.

A divulgação científica é uma prática social que vem sendo cada vez mais ampliada e desenvolvida e, nesse aspecto, os museus ganham destaque como locais de comunicação e de educação não formal. Nesse sentido, o trabalho desenvolvido em tais instituições pode vir a complementar o ensino formal, estabelecido no espaço escolar e mesmo o informal, de modo a acrescentar ou modificar concepções obtidas por meio do senso comum. (INOCÊNCIO, 2012, p. 1)

Vieira (2005, p. 21) enfatiza o significado da educação não formal. Reforça que embora esteja evidenciada a não formalização, é preciso que este processo seja bem conduzido e que tenha pré-definido um determinado objetivo. É preciso uma definição prévia sobre o que se pretende ao submeter os alunos a uma imersão nestes espaços cada vez mais interessantes ao complementarem o trabalho pedagógico.

A educação, enquanto forma de ensino-aprendizagem, é adquirida ao longo da vida dos cidadãos e, segundo alguns autores, pode ser dividida em três diferentes formas: educação escolar formal desenvolvida nas escolas; educação informal, transmitida pelos pais, no convívio com amigos, em clubes, teatros, leituras e outros, ou seja, aquela que decorre de processos naturais e espontâneos; e educação não formal, que ocorre quando existe a intenção de determinados sujeitos em criar ou buscar determinados objetivos fora da instituição escolar. Assim, a educação não formal pode ser definida como a que proporciona a aprendizagem de conteúdos da escolarização formal em espaços como museus, centros de ciências, ou qualquer outro em que as atividades sejam desenvolvidas de forma bem direcionada, com um objetivo definido. (VIEIRA, 2005, p. 21)

Em assim sendo, deve-se sublinhar que nestes espaços é possível, e torna-se muito mais importante e significativo, a construção de conhecimentos a partir da resolução de problemas fazendo com que os estudantes participem de forma mais ativa de sua própria educação. Ainda, é preciso ressaltar que existe uma discussão sobre o se considera 
um espaço não formal de educação. Oliveira (2014, p. 229), justifica o uso do termo "não formal" de maneira clara, o que nos alinha em termos de concordância com o autor.

Embora não haja consenso com relação à definição do que vem a ser um espaço não formal de educação, adota-se aqui a definição segundo a qual tal espaço pode ser qualquer local, diferente do ambiente escolar, institucional ou não, onde se podem exercer atividades educativas. Por outro lado, uma atividade de educação não formal é toda aquela organizada fora do sistema escolar oficial, o qual é obrigatório e regulamentado em níveis. Esta ocorre de maneira voluntária, não sequencial, flexível e guiada por necessidades e motivações intrínsecas do indivíduo. (OLIVEIRA, 2014, p. 229)

Com relação a esta realidade que vem se estabelecendo - os museus cada vez mais presentes no cotidiano da aprendizagem escolar - é preciso que voltemos nossos olhares ao seu público, sejam eles alunos ou demais visitantes. $\mathrm{O}$ fato é que em qualquer destas duas condições, aquilo que se aprende e as formas com que se aprende nos museus, abrange um modo complexo e não fragmentado na relação visitante/experimento.

Valente (2005, p. 182) contribui para a discussão:

A temática voltada para a relação público-museu vem ganhando amplo espaço em fóruns de discussão e publicações das áreas das ciências sociais, bem como tem se diversificado em interesses que abarcam inúmeros aspectos, desde os diversos tipos de museus até os diferentes públicos, estes igualmente desdobrados segundo gênero, idade, formação e procedência, entre outros. Os temas também se relacionam a várias problemáticas de caráter científico ou social, envolvendo disciplinas de campos distintos. No leque dessas possibilidades de estudo, os museus de ciência se situam em um setor particular, vinculado às questões da divulgação científica e suas implicações com o entendimento público da ciência. (VALENTE, 2005, p. 182)

Como porta de entrada em definitivo, no sentido de unir o ambiente museal ao de sala de aula, observam-se a partir dos temas transversais propostos a partir dos Parâmetros Curriculares Nacionais (PCNs) (BRASIL, 1998) a possibilidade viva para integrar estas duas realidades. Funcionam como válvula de escape para que os professores possam trabalhar temas relevantes à formação humana calcada em valores que acaba por perder espaço em detrimento à ênfase que acaba sendo dada aos conhecimentos técnicos, específicos, trabalhados dentro de disciplinas isoladas e muitas vezes sem conexão com a realidade e com o cotidiano dos alunos.

Soares e Silva (2013, p. 178) acrescentam: 
Os experimentos e as narrativas presentes no museu não estão necessariamente ligadas ao currículo escolar, permitindo escolhas diversificadas de exploração deste espaço, tanto em relação aos conteúdos científicos, como aos recursos de comunicação e uso didático. Nos museus, as narrativas construídas em torno dos objetos são apreendidas pelos visitantes de forma autônoma e em um tempo próprio, a partir de contextos pessoais, determinados por experiências prévias, interesses e crenças. Nos museus, os visitantes escolhem o que aprender, quando aprender, com quem e durante quando tempo pretendem aprender. $\mathrm{Na}$ escola, normalmente estas escolhas estão fora do controle dos alunos e até mesmo dos professores. Além disso, diferentemente do que ocorre normalmente nos museus, na escola, os alunos são avaliados em relação à aprendizagem decorrente de uma atividade planejada pelo professor. (SOARES; SILVA, 2013, p. 178)

Na esteira disto, o que se pode perceber é que a transversalidade acaba por favorecer o trabalho transdisciplinar. Os temas atravessam as disciplinas formais e são trabalhados a partir do contexto social, ressignificando a relação dos próprios alunos com o conhecimento e dando sentido às práticas educativas que passam a abranger múltiplos espaços. Oliveira (2014, p. 228) corrobora:

Os Parâmetros Curriculares Nacionais do Ensino Médio (PCNEM) têm por objetivo central facilitar a organização do trabalho da escola. A ideia é orientar a transformação do Ensino Médio, estabelecendo-o como etapa conclusiva da Educação Básica, e não mais como simplesmente preparatório para o Ensino Superior ou estritamente profissionalizante. Portanto, a programação de aulas curiosas, agradáveis, interessantes, interdisciplinares e contextualizadas não só é lei, como, também, é um direito do aluno. Por sua vez, as Orientações Curriculares para o Ensino Médio recomendam o desenvolvimento de práticas fora do espaço escolar, apontando esse procedimento como atividade motivadora, já que desloca o ambiente de aprendizagem para fora de sala de aula. (OLIVEIRA, 2014, p. 228)

Existe ainda uma vantagem adicional na transdisciplinaridade. São as denominadas áreas de sombreamento que se constituem nas franjas, nos limites das disciplinas formais. Um espaço que não costuma a ser preenchido quando se enfatiza a disciplina. Nestes espaços se criam condições de possibilidade para que não apenas as áreas duras encerradas dentro das disciplinas se toquem, mas também possibilitam a interconexão entre os próprios temas transversais podendo constituir uma forma de ensinar diferenciada e motivadora porque o estudante se enxerga como parte desta realidade que está a aprender e a apreender. Bomfim (2013, p. 29) exemplifica estas possíveis relações. 
Os temas transversais, na verdade, podem se tocar constantemente, além de estarem relacionados com vários outros temas; são inúmeras as fronteiras e as interfaces. A 'orientação sexual' toca no tema 'saúde'; este, no de 'meio ambiente'; e todos se relacionam com 'trabalho e consumo', assim como poderiam relacionar-se com 'ética', e esta com 'política' (mesmo em seu sentido estrito, de organização partidária ou de governo). Não obstante, a 'ética', por exemplo, um tema amplo, poderia dar conta de todos esses assuntos, dependendo do encaminhamento dado por um educador. (BOMFIM, 2013, p. 29)

O próprio autor ainda enfatiza o que justifica a opção pelo trabalho com os temas transversais e a sua possível relação com as disciplinas formais.

Na verdade, o que justifica um 'tema transversal' acaba sendo um contexto social, cultural e histórico. Assim, para não dizer que num tema transversal cabe qualquer coisa, ele será mais adequado quando prezado por boa parte da sociedade e justificado por um contexto, mesmo que não se relacione imediatamente com as diferentes disciplinas. (BOMFIM, 2013, p. 29)

Oliveira (2014, p. 228) ainda reforça a importância deste trabalho ao mesmo tempo em que tece uma crítica em relação à condução do trabalho com os temas transversais a partir das proposições dos PCNs.

Contudo, a realidade da tradição escolar está muito longe do que seria necessário para que essa nova escola cumpra as orientações dos PCNEM. A realidade nos traz atividades padronizadas sem inserção em contextos reais, colocando os alunos em atitude de passividade frente ao aprendizado. Não são preocupações escolares as perspectivas profissionais, sociais ou pessoais dos alunos, ou os problemas e desafios da comunidade, da cidade, do país ou do mundo. Na escola, de modo geral, o indivíduo interage com um conhecimento essencialmente acadêmico, sobretudo através da transmissão de informações, supondo que o estudante, memorizando-as passivamente, adquira o conhecimento desejado. (OLIVEIRA, 2014, p. 228)

O que fica claro na citação de Oliveira (2014, p. 228) é que a opção pela transversalidade não garante uma aprendizagem significativa se os professores não planejarem as atividades tanto em termos de objetivos que se pretendem alcançar, quanto das estratégias metodológicas empregadas. No caso específico do MCT-PUCRS, a Coordenadoria Educacional disponibiliza alguns roteiros de atividades que podem ser realizadas em sua área de exposição. Isto não impede que estas também sirvam apenas de inspiração para que professores e até mesmo os próprios alunos planejem e elaborem seus próprios roteiros de atividade. 
Os PCNs ainda trazem a justificativa pela escolha dos temas transversais. Muitos podem ser estes temas que atravessam o corpo de conhecimento das disciplinas isoladas, mas critérios como a realidade, relevância, possibilidade de serem ensinados e urgência social acabam por se configurarem como elementos que justificam sua escolha (BRASIL, 1998). Exatamente esta questão aparece bem assinalada no texto de Bomfim (2013, p. 29).

O corpo técnico que escolheu os temas transversais justificou a escolha com base em quatro critérios: urgência social; abrangência nacional; possibilidade de ensino e aprendizagem; e favorecimento à compreensão da realidade e à participação social [...] 'tratam de processos que estão sendo intensamente vividos pela sociedade, pelas comunidades, pelas famílias, pelos alunos e educadores em seu cotidiano'. (BOMFIM, 2013, p. 29)

Bomfim ainda acentua o efeito da Lei de Diretrizes e Bases da Educação Nacional (LDB) - da qual derivaram os temas transversais - por sobre os documentos da escola, mais especificamente os Projetos Político-Pedagógicos (PPPs).

A Lei de Diretrizes e Bases da Educação Nacional estabelece como uma das incumbências das escolas a elaboração de um projeto com propostas pedagógicas, com a garantia de participação dos profissionais de educação. Só que em vez de se tornar a materialização de um ato democrático e participação no poder, o projeto político-pedagógico passou a ser mais uma das obrigações burocráticas que devem ser cumpridas pelas escolas. Ao estudarmos os PPPs de algumas escolas, constatamos que os PCNs, mais do que qualquer outro documento, se fizeram presentes. (BOMFIM, 2013, p. 44)

De fato, existe uma presença muito acentuada dos PCNs por sobre os PPPs, o que por um lado poderia acarretar na queda destes temas no senso comum de uma educação burocrática. Como se o tema que ali se encontra, pelo simples fato de estar ali, de constar no documento devesse ser trabalhado a qualquer custo. O perigo está no fato de que possa existir a possibilidade de uma inserção cotidiana esvaziada pela má condução que o próprio professorado pode dar durante o trabalho com estes temas.

A partir disto, podemos agora de maneira mais clara inserir o museu neste contexto, o que justifica nosso artigo. A ideia de observar o museu como espaço que visa impulsionar funções educacionais, mas também sociais promovendo o conhecimento à sociedade em geral. É isto também que o caracteriza como espaço não formal de educação e de grande relevância para a produção de saberes. Constitui-se como terreno fértil para a transversalidade, que busca estabelecer uma compreensão do conhecimento sistematizado e as questões sociais presentes no cotidiano dos 
mesmos. Desta forma, para uma educação cidadã é necessário o envolvimento do conhecimento e sua cientificidade, com as questões da vida real. E o Museu como espaço de educação, é o cenário propício tanto como "peça-chave" para construção de conhecimentos como para intervenção social.

O MCT-PUCRS apresenta em sua área expositiva um acervo com cerca de 750 experimentos interativos, disponíveis em três pavimentos e dois mezaninos. De forma geral, cada pavimento envolve determinados eixos temáticos, ou seja, está subdividido em áreas do conhecimento científico. No primeiro pavimento são abordados assuntos relacionados às áreas "Educação Ambiental", "Cetáceos", entre outras; no segundo pavimento estão presentes áreas como "Biodiversidade", "Ciência e Cuidado", "Corpo Humano", "Planeta Terra", "Universo" e "Paleontologia". E no terceiro pavimento estão presentes áreas como "Força e Movimento", "Matéria e Energia", "Eletricidade e Magnetismo", "Ondas e Som", entre outras voltadas principalmente para o ensino de Física.

A partir desta breve descrição sobre a organização das áreas nos diferentes pavimentos do MCT-PUCRS, fica evidenciada a possibilidade da realização - por meio das áreas destacadas anteriormente - de uma abordagem de forma transversal dos temas presentes e sugeridos pelos PCNs. Em assim sendo, se torna possível a elucidação da relação entre os conteúdos científicos presentes nos experimentos e uma ampliação do conhecimento para além dos limites da sala de aula. Por exemplo, poderíamos destacar temas transversais como "saúde" e "meio ambiente" e a partir deles promover a reflexão sobre como conteúdos específicos podem ser ensinados a partir da transversalidade, partindo do interesse dos próprios alunos sobre o que eles se interessariam em pesquisar sobre estes temas.

Neste caminho o professor faria o sentido inverso. Ao invés de partir de um ensino das partes, do específico em relação ao todo, existe a possibilidade de partir do real, do macro, do palpável, e então por meio de atividades previamente planejadas, poderia ir especificando ou promovendo a pesquisa em sala de aula na figura de um aluno partícipe de seu aprendizado. Geralmente, o que se observa quando se trabalha com a pesquisa bem conduzida em sala de aula, é um aluno engajado e reflexivo que passa a enxergar a importância da contextualização na resolução de problemas exercendo um protagonismo que em última análise deve ser convertido na transformação de sua própria realidade, na realidade social da qual faz parte. Por fim, um aluno que toma consciência da dimensão de seus próprios conhecimentos.

No caso do MCT-PUCRS, observa-se a possibilidade de, por meio da interatividade, um conhecimento teórico ser abordado na prática. A interação com os experimentos, em toda visitação, remete a reflexão sobre o quão importante se configuram práticas pedagógicas dinâmicas e motivadoras, tanto em espaços não formais, quanto espaços formais de educação. As experimentações e a cientificidade presente na interação com os experimentos proporcionam uma metodologia diferenciada, e facilitam a compreensão do visitante e/ou aluno. Além disso, promovem a construção do conhecimento consolidado em um âmbito transdisciplinar ou ainda, consolidam um conhecimento construído no 
âmbito disciplinar observado agora sob um viés transdisciplinar e, sendo assim, fazem ultrapassar o conhecimento fragmentado, permitindo uma ampliação e aprimoramento do mesmo.

Ubiratan D'Ambrosio (1997, p. 80) observa sobre a transdisciplinaridade em sua relação com a questão da fragmentação do conhecimento, herança disciplinar ainda Moderna.

A transdisciplinaridade é transcultural na sua essência. Implica num reconhecimento de que a atual proliferação das disciplinas e especialidades acadêmicas e não-acadêmicas conduz a um crescimento incontestável de poder associado a detentores desses conhecimentos fragmentados. [...] Além disso, o conhecimento fragmentado dificilmente poderá dar a seus detentores a capacidade de reconhecer e enfrentar tanto problemas quanto situações novas que emergem em um mundo complexo. (D'AMBROSIO, 1997, p. 80)

Ainda, tendo em vista os múltiplos enfoques que podem conduzir uma aprendizagem transdisciplinar no espaço museal, cabe lembrar que no MCT-PUCRS, existe ainda a figura do mediador. Ele não substitui o papel do professor, mas ajuda na compreensão do funcionamento dos experimentos e dos processos envolvidos em sua ocorrência. A mediação é fundamental para que aquele que interage se coloque em uma posição de melhor compreensão acerca do que está observando. Neste contexto, para que ocorra um processo de construção e significação do conhecimento é necessária uma relação de mediação entre o conhecimento presente no experimento, e o conhecimento prévio do visitante e/ou aluno. Ou seja, para que a mediação seja realizada é fundamental a presença do mediador e/ou professor. Pois, é através da troca de saberes entre ambos que será oportunizado a (re)construção de um conhecimento questionador e crítico. A mediação por vezes permite uma contextualização não apenas atual, mas histórica do processo ou fenômeno. Como explicita Pedro Demo (2011, p. 9):

[...] não se pode reduzir o questionamento reconstrutivo à simples competência formal da aprendizagem, mas é crucial compreendê-lo como processo de construção do sujeito histórico, que se funda na competência advinda do conhecimento inovador, mas implica, na mesma matriz, a ética da intervenção histórica. (DEMO, 2011, p. 9)

A partir disto, de que maneira poderiam ser explorados os temas transversais "saúde" e "meio Ambiente" na área de exposição do MCT-PUCRS? É exatamente esta a proposta deste artigo: a possibilidade de trabalhar estes temas a partir da perspectiva transversal, considerada por nós, mais relevante e significativa. Cabe lembrar aqui a necessidade de uma cisão entre o conhecimento formalizado - ensinado em sala de aula - e as possibilidades que se descortinam 
em um espaço de educação não formal como o museu. Com isto, o conhecimento formal, o conteúdo em si passa a estar inscrito em uma condição que é a da instrução que difere do que se considera como educação, e que passa a ser contemplado pela própria transversalidade. A instrução em áreas como saúde e meio ambiente diz respeito ao uma série de conceitos específicos, mas uma educação em saúde e meio ambiente tem uma amplitude maior na medida em que requer elementos que vão além dos conteúdos básicos - muitas vezes trabalhados sem significação alguma -, mas abrangem práticas de cuidado de si, dos outros e do espaço de convivência social.

O tema saúde pode ser explorado principalmente a partir da exposição "Ciência e cuidado" (no segundo pavimento do MCT-PUCRS) que aborda o papel de Florence Nightingale no desenvolvimento de práticas de cuidado ligadas à constituição da enfermagem como ofício, profissão. Ainda, experimentos que trazem a distinção entre doenças virais e bacterianas, o trabalho a partir do conceito de higiene e as medidas profiláticas envolvidas que poderiam ser abordadas pelo tipo de costumes relacionados à própria higiene que fazem parte do dia-a-dia dos alunos, como o hábito de lavar as mãos ou tomar banho. Partindo daquilo que faz parte de sua própria realidade, da avaliação de seus hábitos de higiene, além da profilaxia, diferenças entre agentes infecciosos - em termos de classificação nos domínios da vida e sua morfologia -, a natureza infecciosa de determinadas doenças etc. Ainda podemos considerar o museu como espaço de interação público-público, onde próprio aluno pode - a partir de uma proposta de pesquisa - entrevistar os demais visitantes, coletar dados para posteriormente tabulá-los iniciandose assim também em práticas de pesquisa quantitativa. O que mais tarde poderá, até mesmo, proporcionar um aprimoramento dos estudantes na alfabetização científica no que diz respeito a construção e a leitura de gráficos e tabelas.

Ainda no segundo pavimento do MCT-PUCRS, temos uma área específica que se refere ao corpo humano. Desde a concepção até o corpo constituído podem ser percebidos e estudados, sob múltiplos enfoques como proporciona a transversalidade, elementos sobre a anatomia e a fisiologia. Tais elementos podem ser abordados no sentido de melhorar a compreensão dos estudantes sobre como o corpo humano se organiza e como se dá o seu funcionamento em termos de processos fisiológicos. O professor pode inculcar o hábito da pesquisa e da resolução de problemas a partir da elaboração de perguntas, problemas de pesquisa considerados geradores de todo um processo de aprendizagem cujos desdobramentos passam a ser imprevisíveis, tendo em vista o envolvimento dos próprios alunos que pode conduzir a mais perguntas interessantes. Partindo desta realidade de imersão no universo da pesquisa, pode ser estabelecido um planejamento estratégico sobre como serão resolvidos os problemas contidos nos questionamentos. Em um espaço como o MCT-PUCRS a resposta pode estar na própria relação de um experimento com outro. Para isto, a figura da mediação e a percepção do aluno no intuito de relacionar elementos presentes nos experimentos são fundamentais. 
O tema saúde pode ser ainda abordado a partir de experimentos que abordem a temática da água. A água que é essencial à vida, o que nos faria retornar ao segundo pavimento para trabalharmos a origem da vida e até mesmo na área dos dioramas - que representam ecossistemas - seres vivos que contribuem para a saúde humana ou que de certa forma causam prejuízo. Cabe lembrar que embora o terceiro pavimento aborde experimentos ligados a área de Física, pode-se propor uma pesquisa sobre como a Física Mecânica se relaciona com a execução dos movimentos corporais ou até mesmo a importância da eletricidade associada à saúde e ao bem-estar da humanidade.

Como citamos anteriormente, existe uma possibilidade de interconexão entre os temas conversais. Ao trabalhar a questão da saúde relacionada à temática da água e a dos ecossistemas estamos relacionando "saúde" com "meio ambiente", ou seja, a fragmentação que o aluno perceberia em sala de aula no museu torna-se uma coisa só: um aprendizado único, consistentemente consolidado e significativo. Neste caso, o estudante não percebe o aprendizado como algo separado, segregado. Para além da instrução se exerce a possibilidade de uma educação permeada por elementos de socialização.

O tema transversal "meio ambiente" pode ser abordado desde o primeiro pavimento do MCT-PUCRS. A área de biodiversidade pode ser o ponto de partida para que o aluno tome conhecimento da diversidade de seres vivos que povoa nosso planeta. Ainda, se o professor quiser abordar a biodiversidade em sua essência - as causas das diferenças - pode, no segundo pavimento, explorar a molécula de DNA e sua constituição, além do painel que aborda o darwinismo, a seleção natural e como resultado o processo evolutivo. Além disso, ainda no pavimento, a exposição sobre motores e tipos de combustíveis, pode-se propor uma discussão sobre como o efeito destes motores a partir da queima de diferentes combustíveis, afeta o meio ambiente. Poderíamos tocar ainda, neste sentido na questão do consumo e sobre como a humanidade - principalmente a sociedade capitalista - tem se relacionado com elementos concernentes a este outro tema transversal proposto pelos PCNs. Consumo este, que poderia também ser trabalhado na relação do desperdício de água contemplando "saúde" e "meio ambiente".

Paralelo a isso, é importante que percebamos como esta interação é valiosa para o processo de aprendizagem. Em um espaço como o museal, o visitante é mais senhor da sua própria aprendizagem Isto significa dizer que os próprios alunos adquirem mais autonomia ao aprenderem ou complementarem seu aprendizado no museu. Conforme Soares e Silva (2013, p. 186) colocam:

A essência da experiência museal é o controle pessoal sobre aprendizagem, ou seja, a escolha do que e quando aprender. As experiências interativas do visitante permitem uma maior autonomia nos ambientes museais e estão no âmago da aprendizagem de livre escolha. (SOARES; SILVA, 2013, p. 186) 
O presente artigo não quer encerrar uma maneira de se trabalhar a partir da perspectiva transdisciplinar. Não apenas na realidade do MCT-PUCRS, mas nas de outros museus é possível que se trabalhe os temas propostos, a transversalidade de várias maneiras. $\mathrm{O}$ que propusemos aqui, nestas breves linhas é um caminho dentre vários outros que podem ser seguidos. Os roteiros do MCT-PUCRS são criados a partir daquilo que cada visitante, seja aluno, professor ou um visitante informal acredita que pode estabelecer como sequência lógica de sua própria compreensão.

A ideia central é a de que a transdisciplinaridade faz resultar um currículo-nômade, que se produz no acontecendo (GALLICHIO, 2003). É como se tomássemos como empréstimo a metáfora do rizoma de Guattari e Deleuze (1995). As relações curriculares podem ser trabalhadas a partir de uma ecologia do currículo (FERRARO, 2014), relações estas que se tecem conforme a interação vai se configurando. E é exatamente aí que saímos ganhando ao escolhermos a transdiciplinaridade e os espaços museais.

Acreditamos que é na percepção onde tudo se relaciona com tudo que o conhecimento do aluno se forja de maneira mais plástica e passa a ser mobilizado de maneira rápida em resposta aos problemas cotidianos. Neste sentido cabe ao professor estimular a pesquisa em sala de aula a partir da resolução de problemas. Fazer surgir o aluno pesquisador (DEMO, 2011), o que contribui para uma mudança na relação que o próprio aluno passa a ter com seu conhecimento a partir de uma postura mais ativa, interessada e prazerosa em seu processo de aprendizagem.

\section{Referências}

BOMFIM, Alexandre Maia do et al. Parâmetros curriculares nacionais: uma revisita aos temas transversais meio ambiente e saúde. Trab. Educ. Saúde, v. 11, n. 1, p. 27-52, 2013.

BRASIL. Parâmetros curriculares nacionais. Brasília: Ministério da Educação, 1998.

D’AMBROSIO, Ubiratan. Transdisciplinaridade. São Paulo: Palas Athena, 1997.

DELEUZE, Gilles; GUATTARI, Félix. Mil platôs. São Paulo: Editora 34, 1995. v. 1.

DEMO, Pedro. Educar pela pesquisa. 9. ed. São Paulo: Autores Associados, 2011.

FERRARO, José Luís Schifino. Por uma ecologia do currículo: nova percepção, diferente perspectiva. Revista e-Curriculum, v. 12, n. 1, p. 969-990, 2014.

KROEF, Ada Beatriz Gallicchio. Currículo-nômade: sobrevôos de bruxas e travessias de piratas. 2003. Tese (Doutorado) - Universidade Federal do Rio Grande do Sul. Porto Alegre, 2003.

NAVAS, Ana Maria. Concepções de popularização da ciência e da tecnologia no discurso político: impactos nos museus de ciências. 2008. Dissertação (Mestrado) - Universidade de São Paulo. São Paulo, 2008. 
INOCÊNCIO, Adalberto Ferdnando. Educação ambiental e educação não formal: um estudo de caso na perspectiva de um museu interdisciplinar. In: SEMINÁRIO DE PESQUISA E EDUCAÇÃO DA REGIÃO SUL, IX. (IX ANPED SUL). 2012. p. 1-13.

OLIVEIRA, Guilherme Cordeiro da Graça de et al. Visitas guiadas ao Museu Nacional: interações e impressões de estudantes da Educação Básica. Ciênc. Educ., v. 20, n. 1, p. 227-242, 2014.

SOARES, Charles Tiago dos Santos; DA SILVA, Ana Maria Marques. Escolha e controle em um ambiente museal: um estudo com professores de Ciências. Investigações em Ensino de Ciências, v. 18, n. 1, p. 177-198, 2013.

VALENTE, Maria Esther et al. Museus, ciência e educação: novos desafios. História, Ciências, Saúde, v. 12, supl., p. 183-203, 2005.

VIEIRA, Valéria et al. Espaços não-formais de ensino e o currículo de ciências. Ciência e Cultura, v. 57, n. 4, p. 21-23, 2005.

\section{Endereço para correspondência:}

José Luís Schifino Ferraro

Pontifícia Universidade Católica do Rio Grande do Sul - PUCRS

Faculdade de Biociências

Av. Ipiranga, 6681 - Prédio 12

90619-900 Porto Alegre, RS, Brasil

E-mail: <jose.luis@pucrs.br>

Recebido em: jun./2014

Aceito em: ago./2014 